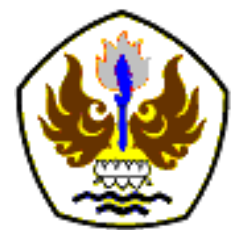

INFOMATEK

Volume 21 Nomor 1 Juni 2019

\title{
KAJIAN MENGENAI KONTAMINASI MIKROORGANISME PADA MAKANAN YANG DIJUAL DI PINGGIR JALAN
}

\author{
Yonik Meilawati Yustiani ${ }^{*}$, Dwi Antono Sigalingging, Herdian Fitranandia, Novia Indriyani \\ Supendi
}

Program Studi Teknik Lingkungan

Fakultas Teknik - Universitas Pasundan

\begin{abstract}
Abstrak: Penjualan makanan di pinggir jalan banyak ditemui di daerah sekitar perkantoran dan area pendidikan. Masyarakat memilih membeli makanan dari penjualan di pinggir jalan dengan alasan harga yang murah dan kemudahan dalam mendapatkannya. Namun kondisi lingkungan yang buruk dapat mengkotaminasi makanan tersebut dengan bakteri penyebab penyakit. Salah satu mikroorganisme yang berpotensi mengkotaminasi makanan adalah Escherichia coli. Bakteri tersebut dapat mengakibatkan penyakit pada sistem pencernaan. Kajian ini dilakukan untuk mengidentifikasi keberadaan Escherichia coli dan coliform pada makanan yang dijual di pinggir jalan pada daerah pendidikan sekitar Jalan Setibabudhi, Kota Bandung. Sampel makanan yang dipilih untuk diuji adalah bakso, buah jambu dan tahu. Uji yang dilakukan di laboratorium mikrobiologi Teknik Lingkungan meliputi uji pendugaan melihat reaksi gas dan asam yang ditimbulkan serta uji penegasan untuk mengidentifikasi keberadaan jenis mikroorganisme yang terkandung dalam sampel makanan tersebut. Uji laboratorium menunjukkan bahwa seluruh jenis sampel, baik bakso, buah jambu maupun tahu teridentifikasi bakteri Escherichia coli. Tingkat kontaminasi yang paling tinggi diperlihatkan oleh tahu. Berdasarkan hasil tersebut, maka direkomendasikan agar higienitas penjual makanan di pinggir jalan ditingkatkan baik dari alat yang digunakan maupun lingkungan penjualan. Isolasi yang baik dapat diterapkan untuk makanan agar tidak terkontaminasi dengan pencemar yang terdapat pada lingkungan. Selain itu, direkomendasikan juga agar konsumen dapat melakukan pemrosesan tambahan sebelum mengkonsumsi makanan tersebut.
\end{abstract}

Kata kunci: Escherichia coli, Kontaminasi Mikroorganisme, Makanan

\section{PENDAHULUAN}

Makanan yang dijual di pinggir jalan merupakan salah satu alternatif bagi masyarakat untuk memenuhi kebutuhan makanan sehari-hari. Kelebihan yang ditawarkan oleh makanan ini adalah kemudahan dalam pembelian dan harganya

*)yonik@unpas.ac.id

Pertama diterima : 11 Februari 2019

Direvisi : 2 Mei 2019

Disetujui untuk publikasi: 31 Mei 2019 yang relatif murah. Faktor yang medorong masyarakat membeli makanan dari penjualan di pinggir jalan antara lain kebiasaan membawa bekal, pengetahuan, sikap, pengaruh teman dan peran orang tua (Afni [1]). Fenomena meningkatnya jumlah penjualan makanan di pinggir jalan terutama terjadi di kota-kota besar termasuk Kota Bandung. 
Penjualan makanan pinggir jalan banyak ditemukan di daerah perkantoran dan area pendidikan (Susana, dkk [2]). Tempat penjualan makanan seperti ini dapat berupa warung terbuka, gerobak makanan, wadah asongan, dll. Kondisi tempat penjualan yang terbuka mengakibatkan tingkat higienitas yang rendah. Mikroorganisme yang dapat mengakibatkan penyakit seperti Escherichia coli dapat terkandung dalam makanan yang dijual di pinggir jalan ini [2]. Kualitas makanan yang buruk dan tercemar Escherichia coli ini dapat menyebabkan penyakit perut seperti diare (Zikra, dkk. [3]).

Tujuan kajian ilmiah ini adalah mengidentifikasi keberadaan mikroorganisme Escherichia coli pada makanan yang dijual di pinggir jalan sekitar area pendidikan di Jalan Setiabudhi, Kota Bandung.

\section{METODOLOGI}

Penelitian ini merupakan penelitian deskriptif observasional. Pemeriksaan kandungan bakteri Escherichia coli menggunakan tiga tahapan uji yaitu uji pendugaan, uji penegasan, dan uji pelengkap menggunakan metode Most Probable Number (MPN) dengan 3 seri tabung (BSN [4], Alang [5]). Pada uji pendugaan, digunakan pengamatan hasil reaksi gas dan asam 24 jam. Jika terjadi reaksi pada uji pendugaan tersebut, maka hal ini menandakan dugaan bahwa proses fermentasi Coliform telah terjadi. Sedangkan pada uji penegasan dan pelengkap, suspect Escherichia coli akan diperlihatkan dari warna yang terbentuk [3].

Pemeriksaan kandungan bakteri tersebut dilakukan dengan 3 kali perulangan di Laboratorium Mikrobiologi Teknik Lingkungan Univesitas Pasundan.

Sampel makanan diambil dari penjualan di pinggir jalan yang terdapat di sekitar area pendidikan di Jalan Setiabudhi, Kota Bandung. Jenis makanan yang diuji adalah bakso, buah jambu dan tahu. Tiga jenis makanan ini dipilih menjadi sampel yang mewakili jenis makanan ringan, buah dan lauk untuk makan berat.

\section{ANALISIS DAN PEMBAHASAN}

\subsection{Hasil Pemeriksaan Laboratorium}

Dari hasil penelitian yang telah dilakukan dengan uji pendugaan dengan metode MPN untuk sampel bakso didapatkan hasil seperti terdapat pada Tabel 1.

Dari Tabel 1 tersebut dapat dilihat bahwa asam terbentuk pada tabung fermentasi sampel bakso $10 \mathrm{ml}$ dan $1 \mathrm{ml}$, dan tidak ditemukan pada tabung $0,1 \mathrm{ml}$. Terlihat juga bahwa gas terbentuk pada tabung fermentasi $10 \mathrm{ml}$ dan tidak teridentifikasi pada tabung fermentasi $1 \mathrm{ml}$ dan 0,1 ml. 
Tabel 1. Pengamatan Hasil Reaksi dari Sampel Bakso

\begin{tabular}{ccc}
\hline \multicolumn{3}{c}{ Pengamatan Hasil Reaksi } \\
\hline $\begin{array}{c}\text { Tabung } \\
\text { Fermentasi }\end{array}$ & Gas & Asam \\
\cline { 2 - 3 } & $\mathbf{2 4}$ jam & 24 jam \\
\hline $10 \mathrm{ml}$ & $\checkmark$ & $\checkmark$ \\
\hline $10 \mathrm{ml}$ & $\checkmark$ & $\checkmark$ \\
\hline $10 \mathrm{ml}$ & $\checkmark$ & $\checkmark$ \\
\hline $1 \mathrm{ml}$ & - & $\checkmark$ \\
\hline $1 \mathrm{ml}$ & - & - \\
\hline $1 \mathrm{ml}$ & - & - \\
\hline $0,1 \mathrm{ml}$ & - & - \\
\hline $0,1 \mathrm{ml}$ & - & - \\
\hline $0,1 \mathrm{ml}$ & - &
\end{tabular}

Tabel 2. Pengamatan Hasil Reaksi dari Sampel Buah Jambu

\begin{tabular}{ccc}
\hline \multicolumn{3}{c}{ Pengamatan Hasil Reaksi } \\
\hline Tabung & Gas & Asam \\
\cline { 2 - 3 } Fermentasi & 24 jam & 24 jam \\
\hline $10 \mathrm{ml}$ & $\checkmark$ & $\checkmark$ \\
\hline $10 \mathrm{ml}$ & $\checkmark$ & $\checkmark$ \\
\hline $10 \mathrm{ml}$ & $\checkmark$ & $\checkmark$ \\
\hline $1 \mathrm{ml}$ & $\checkmark$ & $\checkmark$ \\
\hline $1 \mathrm{ml}$ & $\checkmark$ & $\checkmark$ \\
\hline $1 \mathrm{ml}$ & $\checkmark$ & $\checkmark$ \\
\hline $0,1 \mathrm{ml}$ & $\checkmark$ & $\checkmark$ \\
\hline $0,1 \mathrm{ml}$ & $\checkmark$ & $\checkmark$ \\
\hline $0,1 \mathrm{ml}$ & $\checkmark$ & \\
\hline & &
\end{tabular}

Tabel 2 memperlihatkan bahwa gas dan asam teridentifikasi pada seluruh jenis tabung fermentasi untuk sampel buah jambu. Pada perulangan ketiga untuk tabung fermentasi 0,1 $\mathrm{ml}$ tidak terdapat reaksi asam.

Sampel tahu pada Tabel 3 menunjukkan teridentifkasinya gas dan asam pada seluruh tabung fermentasi, baik pada $10 \mathrm{ml}, 1 \mathrm{ml}$, dan $0,1 \mathrm{ml}$ untuk seluruh perulangan.
Tabel 3. Pengamatan Hasil Reaksi dari Sampel Tahu

\begin{tabular}{ccc}
\hline \multicolumn{3}{c}{ Pengamatan Hasil Reaksi } \\
\hline Tabung & Gas & Asam \\
\cline { 2 - 3 } Fermentasi & 24 jam & 24 jam \\
\hline $10 \mathrm{ml}$ & $\checkmark$ & $\checkmark$ \\
\hline $10 \mathrm{ml}$ & $\checkmark$ & $\checkmark$ \\
\hline $10 \mathrm{ml}$ & $\checkmark$ & $\checkmark$ \\
\hline $1 \mathrm{ml}$ & $\checkmark$ & $\checkmark$ \\
\hline $1 \mathrm{ml}$ & $\checkmark$ & $\checkmark$ \\
\hline $1 \mathrm{ml}$ & $\checkmark$ & $\checkmark$ \\
\hline $0,1 \mathrm{ml}$ & $\checkmark$ & $\checkmark$ \\
\hline $0,1 \mathrm{ml}$ & $\checkmark$ & $\checkmark$ \\
\hline $0,1 \mathrm{ml}$ & $\checkmark$ & $\checkmark$
\end{tabular}

Dari hasil penelitian yang telah dilakukan dengan uji penegasan dengan metode MPN didapatkan hasil pada Tabel 4.

Tabel 4. Pengamatan Hasil Reaksi Uji Penegasan

\begin{tabular}{lcc}
\hline \multicolumn{3}{c}{ Pengamatan Hasil Reaksi } \\
\hline $\begin{array}{c}\text { Jenis } \\
\text { Sampel }\end{array}$ & Positif & Negatif \\
\hline Bakso & $\checkmark$ & - \\
\hline Buah Jambu & $\checkmark$ & - \\
\hline Tahu & $\checkmark$ & - \\
\hline
\end{tabular}

Dari Tabel 4 terlihat bahwa baik pada sampel bakso, buah jambu maupun tahu ditemukan Escherichia coli.

\subsection{Pembahasan}

Hasil pengujian di laboratorium menunjukkan bahwa sampel makanan seperti bakso, buah jambu, dan tahu yang dibeli di pinggir jalan menandakan adanya bakteri golongan coliform dan bakteri E.coli dikarenakan pada uji pendugaan terdapat perubahan warna dan mengandung gelembung. Ketika dipindahkan 
dengan metode gores pada cawan terjadi perubahan warna media sampel bakso menjadi merah muda, media buah jambu menjadi warna merah muda dan untuk media yang digunakan tahu menjadi hijau metalik. Dengan metode MPN ini memerlukan waktu 24 jam untuk melakukan uji penduga, dan membutuhkan waktu 24 jam untuk inkubasi sebagai uji penegasan. Pada saaat melakukan uji penduga dengan cara menginkubasikan pada suhu $37,5^{\circ} \mathrm{C}$ selama 24 jam, pada tabung sampel bakso $10 \mathrm{ml}$ terlihat adanya gas dan asam, sedangkan pada tabung sampel bakso $1 \mathrm{ml}$ rata - rata terlihat adanya gas dan terbentuknya asam, tetapi pada tabung sampel bakso $0,1 \mathrm{ml}$ tidak terlihat adanya gas dan tidak terbentuknya asam. Setelah dilakukan uji penduga, dilakukan uji penegasan untuk menegaskan sampel yang positif mengandung gas dan membentuk asam itu benar benar mengandung bakteri, sampel yang diduga mengandung bakteri dituangkan dalam cawan petri yang berisi NA (Natrium Agar) untuk melihat pertumbahan bakteri yang diindikasikan dengan warna, pada sampel bakso ini terlihat warna merah yang mengindikasikan bahwa adanya bakteri golangan coliform dan bakteri E.coli. Bakteri tersebut bisa menimbulkan penyakit seperti diare akut, muntaber, dll ([1], Pratiwi [6]). Sama halnya dengan menguji sampel lainnya, rata-rata padasaat uji penduga mengandung gas dan terbentuk asam. Biasanya terbentuknya kekeruhan dan gas di dalam tabung durham yang diletakkan pada posisi terbalik yaitu untuk jasad renik membentuk gas $\mathrm{H}_{2} \mathrm{~S}$ (Widiyanti, dkk. [7]).

Dalam sampel makanan yang telah dianalisa menggunakan metode MPN hasil menunjukan positif terdapat mikroorganisme, dan jika dikaitkan dengan kesehatan tubuh maka, orang yang memakan jajanan tersebut lebih besar peluangnya terkena penyakit diakibatkan oleh bakteri yang terdapat di dalam jajanan pinggir jalan tersebut (bakteri golangan coliform dan bakteri E.coli). Sampel makanan tersebut bisa dikatakan tidak layak konsumsi jika melihat dari sudut pandang ada atau tidak adanya mikroorganisme, tetapi masyarakat tetap membeli jajanan tersebut karena tertarik dengan harganya yang relatif murah dan dari segi waktu untuk memperoleh jajanan tersebut yang tidak memakan banyak waktu. Mikroorganisme dalam sampel tersebut dapat berasal dari proses sejak dipindahkan dari alat memasak hingga diberikan kepada pembeli (Rauf [8]). Tangan penjual yang tidak bersih dan alat yang tidak higiensi juga dapat menjadi penyebab kontaminasi bakteri pada makanan. Selain itu, lingkungan yang tercemar, termasuk udara kotor berperan terhadap proses kontaminasi tersebut (Putri, dkk [9]). 
Dengan teridentifikasinya Escherichia coli pada sampel makanan ini, maka rekomendasi yang dapat disarankan antara lain dengan meningkatkan higienitas penjual makanan di pinggir jalan tersebut, yaitu dengan memperhatikan kebersihan alat dan lingkungan tempat berjualan.

Selain itu proses konsumen juga dapat melakukan pencegahan terhadap penyakit yang berpotensi dibawa oleh bakteri dari makanan, yaitu dengan cara mengolahnya kembali sebelum dikonsumsi. Kebiasaan baik terhadap perilaku sehari-hari perlu ditanamkan terutama dari lingkungan keluarga (Rachman [10])

\section{KESIMPULAN}

Pada pokok pembahasan dan hasil data dapat disimpukan beberapa hal sebagai berikut:

1. Terdapat mikroorganisme yang teridentifikasi pada makanan yang dijual di pinggir jalan yaitu bakteri golongan coliform dan bakteri E.coli.

2. Jenis makanan yang potensi terkontaminasi paling tinggi adalah tahu sebagai bagian dari lauk makanan berat.

3. Cara mencegah jajanan pinggir jalan supaya tidak terkontaminasi oleh mikroorganisme adalah dengan meningkatkan higienitas dan meminimalisir jajanan kontak langsung dengan lingkungan yang tercemar.

\section{DAFTAR PUSTAKA}

[1] Afni, N. "Faktor-faktor yang Berpengaruh Terhadap Perilaku Konsumsi Makanan Jajanan di SDN Natam Kecamatan Badar Tahun 2017," Jurnal Berkala Kesehatan, vol. 3 no. 2, pp. 59-66, 2017.

[2] Susana, D., Indrawani, Y.M., Zakianis. "Kontaminasi Bakteri Escherichia coli pada Makanan Pedagang Kaki Lima di Sepanjang Jalan Margonda Depok, Jawa Barat," Kesmas National Public Health Journal, vol. 5, pp. 110-115, 2010.

[3] Zikra, W., Amir, A., Putra, A.E., "Identifikasi Bakteri Escherichia coli (E.coli) pada Air Minum di Rumah Makan dan Café di Kelurahan Jati serta Jati Baru Kota Padang”, Jurnal Kesehatan Andalas, vol. 7 no. 2, pp. 212-216, 2018.

[4] Badan Standarisasi Nasional. SNI 012332-1991: Cara Penentuan MPN (Most Probable Number). Jakarta: Badan Standarisasi Nasional, 1991.

[5] Alang, H., "Deteksi Coliform Air PDAM di Beberapa Kecamatan Kota Makassar," Prosiding Seminar Nasional Mikrobiologi Kesehatan dan Lingkungan, ISBN978-60272245-0-6, 29 Januari 2015.

[6] Pratiwi, L. R. "Hubungan antara Personal Hygiene dan Sanitasi Makanan dengan Kandungan E. coli pada Sambal yang disediakan Kantin Universitas Negeri 
Semarang Tahun 2012," Unnes Journal of Public Health, vol. 3 no. 4, pp. 17-26, 2014.

[7] Widiyanti, N.L.P.M., Ristiani, N.P., "Analisis Kualitatif Bakteri Koliform pada Depo Air Minum Isi Ulang di Kota Singaraja Bali," Jurnal Ekologi Kesehatan, vol. 3 no. 1, pp. 64-73, 2004.

[8] Rauf, R. Sanitasi Pangan dan HACCP. Edisi Pertama. Yogyakarta: Graha IImu, 2013.

[9] Putri, A.M., Kurnia, P., “Identifikasi Keberadaan Bakteri Coliform dan Total Mikroba dalam Es Dung-Dung di sekitar Kampus Universitas Muhammadiyah Surakarta," Media Gizi Indonesia, vol. 13 no. 1, pp. 41-48, 2018.

[10] Rachman, I., Matsumoto, T., Yustiani, Y.M., “Influence of Parents' Behavior to Children Awareness on the Environmental Preservation", Journal Sampurasun: Interdisciplinary Studies for Cultural Heritage, vol. 1, no. 1, pp. 1-6, 2015. 